\title{
Respiratory symptoms, lung function and use of health services among unemployed young adults in Spain
}

\author{
M. Kogevinas*, J.M. Antó*, A. Tobias*, J. Alonso**, J. Soriano*, E. Almar+, N. Muniozguren", \\ F. Payo", A. Pereira\$, J. Sunyer*, for the Spanish Group of the European Community \\ Respiratory Health Survey
}

Respiratory symptoms, lung function and use of health services among unemployed young adults in Spain. M. Kogevinas, J.M. Antó, A. Tobias, J. Alonso, J. Soriano, E. Almar, N. Muniozguren, F. Payo, A. Pereira, J. Sunyer, for the Spanish Group of the European Community Respiratory Health Survey. CERS Journals Ltd 1998.

ABSTRACT: The association of respiratory symptoms, lung function and use of health services with employment status was examined in Spain, a country with a high rate of unemployment.

A population sample comprising 179 unemployed and 1,868 employed subjects aged 20-44 yrs in 1993, was randomly selected from a base population of about 170,000 people in five urban and rural areas of Spain. Subjects completed a questionnaire on respiratory symptoms, sociodemographic and lifestyle factors, occupational exposure and use of health services, and performed a forced spirometry, a methacholine challenge test and blood tests.

Unemployed subjects had a higher risk of simple chronic bronchitis (odds ratio $=\mathbf{2 . 0 6}, 95 \%$ confidence interval 1.30-3.24) and of bronchitis-type symptoms, than those who were employed. These risks were, in part, due to the higher prevalence of smoking, poorer housing and prior occupational exposures among unemployed than among employed people. Smaller differences were found between employed and unemployed subjects for asthma-type symptoms, atopia and lung function tests. Use of health services among subjects with respiratory symptoms was similar among employed and unemployed subjects, except that the latter consistently reported less frequent contact with specialized practitioners.

Unemployed subjects had a higher risk of bronchitis-type symptoms than employed subjects. In Spain's national, free-access healthcare system, the differential use of specialized health services by employment status is likely to imply differences in the characteristics of the healthcare provided.

Eur Respir J 1998; 11: 1363-1368.
*Respiratory and Environmental Health Research Unit and **Health Services Research Unit, Institut Municipal d'Investigació Mèdica (IMIM), Barcelona. +Servicio Neumología, Hospital General, Albacete. 犃ept of Epidemiology, Dirección de Salud de Vizcaya, Bilbao. "Instituto Nacional de Silicosis, Oviedo. \$Hospital General "Juan RamónJiménez", Huelva, Spain.

Correspondence: M. Kogevinas, Respiratory and Environmental Health Research Unit, Institut Municipal d'Investigació Mèdica (IMIM), 80 Doctor Aiguader Rd, 08003 Barcelona, Spain, Fax: 3432213237

Keywords: Asthma

bronchitis

health services

unemployment

Received: May 141997

Accepted after revision February 281998

The study was partly funded by the Fondo de Investigación Sanitaria Spain (FIS, grant 93/0393) and by CIRIT, Spain (GRQ939304). M. Kogevinas was partly supported by the Dirección General de Investigación Cientifica y Técnica, Ministry of Education and Science, Spain (SAB95-0189).
The unemployed have a higher risk of psychiatric diseases than the employed, and a higher prevalence of highrisk behaviours such as smoking and drinking. Recent cross-sectional and cohort studies have found an increased mortality or morbidity among unemployed people from all causes, all cancers and lung cancer, cardiovascular diseases and accidents [1-7]. Morbidity and mortality from other diseases, including respiratory diseases (asthma, bronchitis and emphysema combined), has hardly been examined $[1,5,8]$. The poorer health associated with unemployment or anticipated unemployment has been attributed to the direct or indirect effects of unemployed status, such as poverty, relative poverty, stress and changes in health-related behaviours $[9,10]$. The selection of individuals who are out of employment because of illness has also been proposed as one of the causes for the higher morbidity of unemployed people, although the extent of this type of bias has been questioned [11]. Employment status has not been consistently associated with differ- ences in the frequency of use of health services, at least in countries with national health systems providing universal free-access to healthcare [12-14].

Spain has one of the highest rates of unemployment among European countries [15]. A study was conducted on the prevalence of respiratory symptoms in a random sample of young adults, and form part of the European Community Respiratory Health Survey [16. 17]. In this paper the respiratory health of unemployed subjects compared with employed subjects is examined, along with determinants of their variation in respiratory health and differences in the access to and use of healthcare.

\section{Methods}

A random sample $(n=16,884)$ of the population aged 20-44 yrs living in five areas of Spain was contacted and asked to complete a short screening questionnaire on respiratory symptoms. In a second phase of the study 4,342 
subjects, corresponding to a $20 \%$ random subsample of the study population $(n=3,310)$ and a complementary "symptomatic" subsample $(\mathrm{n}=1,032)$ were contacted. The latter included all those subjects who had not been selected in the random subsample but who had reported asthmarelated symptoms in the screening questionnaire.

In this second phase, subjects were asked to complete a long questionnaire (71 stem questions), to perform a forced spirometric test, to provide blood samples and to determine bronchial reactivity through a methacholine challenge test $[16,17]$. The long questionnaire was completed by 2,646 subjects (response rate $61 \%$ ). Of these, 599 subjects were classified as inactive and excluded (e.g. housewives, students) and the remaining 2,047 subjects constituted the population for the study on unemployment and health (table 1). Subjects in the active population who reported not to be working as employees or self-employed at the time of the survey in 1993, and who declared that they were looking for a job, were classified as unemployed. The def-

Table 1. - Description of the study population by employment status

\begin{tabular}{|c|c|c|c|c|}
\hline & \multicolumn{2}{|c|}{ Employed } & \multicolumn{2}{|c|}{ Unemployed } \\
\hline & $\mathrm{n}$ & $\%$ & $\mathrm{n}$ & $\%$ \\
\hline \multicolumn{5}{|l|}{ Area* } \\
\hline Albacete & 425 & 22.7 & 27 & 15.1 \\
\hline Barcelona & 403 & 21.6 & 30 & 16.8 \\
\hline Galdakao & 432 & 23.1 & 40 & 22.3 \\
\hline Huelva & 250 & 13.4 & 41 & 22.9 \\
\hline Oviedo & 358 & 19.2 & 41 & 22.9 \\
\hline \multicolumn{5}{|l|}{ Sex* } \\
\hline Male & 1054 & 56.4 & 66 & 36.9 \\
\hline Female & 814 & 43.6 & 113 & 63.1 \\
\hline \multicolumn{5}{|l|}{ Age yrs } \\
\hline 20-29 & 665 & 35.6 & 75 & 41.9 \\
\hline $30-39$ & 786 & 42.1 & 73 & 40.8 \\
\hline $40-44$ & 417 & 22.3 & 31 & 17.3 \\
\hline \multicolumn{5}{|l|}{ Smoking status ${ }^{\dagger}$} \\
\hline Nonsmokers & 572 & 31.2 & 47 & 26.5 \\
\hline Exsmokers & 275 & 15.0 & 26 & 14.7 \\
\hline Current smokers & 986 & 53.8 & 104 & 58.8 \\
\hline Pack-yrs, low & 333 & 18.2 & 26 & 14.7 \\
\hline Pack-yrs, middle & 289 & 15.8 & 42 & 23.7 \\
\hline Pack-yrs, high & 364 & 19.8 & 36 & 20.3 \\
\hline \multicolumn{5}{|l|}{ Passive smoking } \\
\hline No & 438 & 23.5 & 47 & 26.3 \\
\hline Yes & 1430 & 76.5 & 132 & 73.7 \\
\hline \multicolumn{5}{|l|}{ Mould in house } \\
\hline No & 1391 & 74.5 & 125 & 69.8 \\
\hline Yes & 476 & 25.5 & 54 & 30.2 \\
\hline \multicolumn{5}{|c|}{$\begin{array}{l}\text { Occupational exposure to vapours, } \\
\text { gases, dusts or fumes }\end{array}$} \\
\hline No & 1414 & 75.7 & 133 & 74.3 \\
\hline Yes & 454 & 24.3 & 46 & 25.7 \\
\hline \multicolumn{5}{|c|}{$\begin{array}{l}\text { Employment in high-risk asthma } \\
\text { occupation }\end{array}$} \\
\hline No & 1758 & 94.1 & 168 & 93.8 \\
\hline Yes & 110 & 5.9 & 11 & 6.2 \\
\hline \multicolumn{5}{|c|}{$\begin{array}{l}\text { Change of occupation due to } \\
\text { respiratory health problems }\end{array}$} \\
\hline No & 1781 & 95.3 & 166 & 92.7 \\
\hline Yes & 87 & 4.7 & 13 & 7.3 \\
\hline Total & 1868 & 100 & 179 & 100 \\
\hline
\end{tabular}

*: Significant difference, $\mathrm{p}<0.01$. Thirty five employed and two unemployed subjects were smokers solely of pipes or cigars, or had missing information. inition of unemployment was cross-sectional and no information was available on length of unemployment. All remaining subjects among the active population, i.e. the employed subjects, were used as a reference. The classification of employment status, similarly to all other factors examined, was made whilst blind to the subject's disease status.

Subjects reporting respiratory symptoms (cases) were derived from the two subsamples, the random and the symptoms subsample. Controls were derived exclusively from the random subsample. Thus, the number of eligible subjects depended on the specific disease examined. In essence, the study was population based, including all cases identified in the initial random population sample and comparing them with a set of frequency-matched population controls.

The association of employment status with the prevalence of a variety of respiratory symptoms or their combination was investigated. Subjects were questioned concerning the occurrence of respiratory symptoms and diseases during the last 12 months before the interview, particularly cough, phlegm, wheeze, shortness of breath and asthma attacks. Simple chronic bronchitis was defined as a report of coughing and phlegm on most days for at least 3 months each year. Two definitions for asthma were used: 1) asthma symptoms or medication, a report of an attack of asthma during the last 12 months, having been woken by an attack of shortness of breath during the last 12 months, or taking asthma medication presently; and 2) bronchial reactivity and asthma symptoms or medication, a combination of asthma symptoms or medication (as defined above) and bronchial responsiveness. Bronchial responsiveness was defined as a $20 \%$ fall in the forced expiratory volume in one second (FEV1) with respect to the highest FEV1 postdiluent during methacholine challenge with an estimated inhaled methacholine cumulated dose of $8 \mu \mathrm{mol}$. A cumulated methacholine dose of $1 \mathrm{~g}$ $(5.117 \mu \mathrm{mol})$ was administered. The bronchial response to $8 \mu \mathrm{mol}$ of methacholine was estimated by linear extrapolation. Subjects underwent baseline spirometry (Biomedin, Padova, Italy), performing at least three acceptable repeatable (within $5 \%$ or $100 \mathrm{~mL}$ ) manoeuvres to measure forced vital capacity (FVC), FEV1 and mean forced expiratory flow during the middle half of the FVC (FEF $25-75 \%)$. Atopic subjects were defined as those having specific immunoglobulin ( $\mathrm{Ig}) \mathrm{E}$ antibodies to at least one common inhalant allergen (cat, Cladosporium, Dermatophagoides, Parietaria or ragweed) Š $0.34 \mathrm{U} \cdot \mathrm{mL}^{-1}$ by the capsulated hydrophilic carrier polymer (CAP) method.

Information was requested on smoking status (neversmoker, exsmoker, current smoker), duration and intensity of cigarette smoking (combined for this analysis into packyrs categorized in tertiles), exposure to environmental tobacco smoke, housing conditions (occurrence of mould in the house during the last year), current occupation and self-reported occupational exposure to dusts, vapours, gas or fumes (table 1). Any change in occupation due to respiratory health problems was also recorded. Subjects were classified as being at high risk for occupational asthma on the basis of the information on occupation. The group at high risk for asthma was the same as in an earlier study on occupational asthma in this population [18] and included spray painters, electricians, welders and solderers, bakers, rubber and plastic workers, laboratory workers, chemical 
industry processing workers and workers in metal making and treatment. Area of residence was classified into the five large areas from which the subjects were sampled. The frequency of use of health services for any breathing problem, recall period and the type of medical practitioner last contacted were recorded. Analyses of the use of health care focused on subjects reporting respiratory symptoms or disease.

Logistic regression analysis was applied using SAS (Proc Logistic) and EGRET statistical packages [19, 20]. Prevalence odds ratios (OR) and $95 \%$ confidence intervals ( $95 \% \mathrm{CI})$ were adjusted for area of residence (five areas), sex and age (in three strata, 20-29, 30-39, 40-44 yrs). The association between pulmonary function and employment status was calculated using multiple linear regression, adjusting for age, sex, area and height. The best goodness of fit was obtained after controlling for height squared. Age and height were centred by their mean value to provide a meaningful intercept for each parameter of pulmonary function.

\section{Results}

Unemployed subjects constituted about $9 \%$ of the total study population, with the unemployment rate ranging between $6 \%$ (Albacete) and 14\% (Huelva) in the five areas (table 1). A higher unemployment rate was seen among women (12\%), among the youngest age groups (10\%) and in subjects with manual occupations (11\%). In general, a consistently higher prevalence of potential risk factors for respiratory disease was observed in unemployed subjects than in employed subjects, but differences were small (table 1). The prevalence of ever having smoked (and of current smoking) was slightly higher among unemployed (74\%) than employed subjects $(69 \%)$. The unemployed subjects reported a slightly higher prevalence of mould in the house during the last year and a slightly higher frequency of change of occupation due to respiratory health problems, but a similar prevalence of occupational exposure to gases, dusts or fumes, and a lower exposure to environmental tobacco smoke (table 1).
Unemployed subjects had an increased risk for bronchitis-type symptoms compared with employed subjects (table 2). Statistically significant increased risks were observed for simple chronic bronchitis $(\mathrm{OR}=2.06,95 \% \mathrm{CI}$ $1.30-3.24)$, wheezing during the last 12 months (OR= 1.63), "cough first thing in the morning" (OR=1.46), "persistent phlegm" $(\mathrm{OR}=1.73)$ and a report of any breathing problem $(\mathrm{OR}=1.50)$. The results of the multivariate analysis (table 2) suggest that the $106 \%$ increased risk for simple chronic bronchitis among the unemployed could only partly (about $30 \%$ ) be attributed to potential risk factors such as smoking or occupation (table 2). Lower and statistically nonsignificant increased risks were found for asthma and asthma-like symptoms, atopy or an FEV1/FVC ratio $<70 \%$ (table 2 ). There were no statistically significant differences for other lung function parameters by employment status, after adjusting for age (centred), height squared, sex, area, smoking, mould in the house and occupational exposure. A slightly increased FEV1 was observed in unemployed subjects compared with employed subjects $(\mathrm{FEV} 1=32.7 \mathrm{~mL}, \mathrm{SE}=40.8, \mathrm{p}$-value $=0.4$, intercept $=3.898 \mathrm{~mL}$ ). The mean FEF25-75\% was similar between the two groups (FEF25-75\% for unemployed subjects -0.04 $\mathrm{L} \cdot \mathrm{S}^{-1}, \mathrm{SE}=0.1$, $\mathrm{p}$-value $=0.86$, intercept $\left.=4.65 \mathrm{~L} \cdot \mathrm{s}^{-1}\right)$.

Smoking status $(\mathrm{p}<0.001)$ and pack-years $(\mathrm{p}$-value $<0.001)$ were strongly associated with bronchitis, after adjusting for age, sex, unemployment, occupation and housing. Among the other variables examined, self-reported exposure to gases, vapours, dusts and fumes were statistically significant in association with bronchitis (adjusted OR= $1.48,95 \%$ CI 1.04-2.11), while a small increased risk was also found for mould in the house $(\mathrm{OR}=1.25,95 \%$ CI 0.87-1.78). For asthma, among the variables examined, the highest risk was observed for occupational exposure.

There was no association between employment status and frequency of contact with a medical doctor for a breathing problem (table 3). An approximately similar proportion of employed and unemployed subjects with respiratory symptoms had contacted a practitioner during the last 12 months, irrespective of the type of the respiratory symptoms reported. There were, however, clear

Table 2. - Odds ratio for respiratory symptoms and diseases among the unemployed compared to employed (reference) subjects

\begin{tabular}{lccc}
\hline \multicolumn{1}{c}{ Symptoms or disease } & $\begin{array}{c}\text { Subjects } \\
\text { with symptoms } \\
\mathrm{n}\end{array}$ & $\begin{array}{c}\text { Odds ratio } \\
(95 \% \mathrm{CI})^{*}\end{array}$ & $\begin{array}{c}\text { Adjusted odds ratio } \\
(95 \% \mathrm{CI}) \dagger\end{array}$ \\
\hline Morning cough & 451 & $1.46(1.01-2.11)$ & $1.10(0.72-1.28)$ \\
Persistent cough & 363 & $1.34(0.90-1.99)$ & $1.13(0.74-1.74)$ \\
Morning phlegm & 512 & $1.30(0.89-1.88)$ & $1.10(0.73-1.64)$ \\
Persistent phlegm & 335 & $1.74(1.14-2.62)$ & $1.57(1.01-2.45)$ \\
Bronchitis & 223 & $2.06(1.30-3.24)$ & $1.77(1.08-2.90)$ \\
Wheezing, any type & 623 & $1.63(1.17-2.28)$ & $1.47(1.03-2.11)$ \\
Wheezing, without a cold & 371 & $0.99(0.54-1.82)$ & $0.93(0.50-1.73)$ \\
Shortness of breath & 223 & $1.31(0.82-2.11)$ & $1.31(0.81-2.12)$ \\
Asthma symptoms or medication & 384 & $1.38(0.94-2.02)$ & $1.41(0.95-2.07)$ \\
Bronchial reactivity and asthma symptoms or medication & 90 & $1.19(0.54-2.63)$ & $1.30(0.58-2.90)$ \\
Any breathing problem & 397 & $1.50(1.04-2.16)$ & $1.46(1.00-2.13)$ \\
Atopy & 464 & $0.89(0.57-1.40)$ & $0.87(0.55-1.38)$ \\
FEV1/FVC <70\% & 50 & $0.87(0.25-2.99)$ & $0.73(0.20-2.62)$ \\
\hline
\end{tabular}

*: Odds (prevalence) ratios and 95\% confidence intervals (CI) are adjusted for age, sex and area. $\%$ : Odds (prevalence) ratios are additionally adjusted for smoking, occupation (exposure to vapours, dusts, gases or fumes and employment in a high-risk asthma job) and presence of mould in the house. FEV1: forced expiratory volume in one second; FVC: forced vital capacity. 
Table 3. - Frequency of contact with a doctor for a breathing problem among subjects with selected respiratory symptoms or diseases, by employment status

\begin{tabular}{llcc}
\hline $\begin{array}{c}\text { Symptom or } \\
\text { disease }\end{array}$ & Employed & $\begin{array}{c}\text { Subjects } \\
\text { with } \\
\text { symptoms } \\
\mathrm{n}\end{array}$ & $\begin{array}{c}\text { Contacted a } \\
\text { doctor in the } \\
\text { last year } \\
\%\end{array}$ \\
\hline Morning cough & No & 52 & 5.8 \\
Morning phlegm & Yes & 399 & 10.5 \\
& No & 50 & 14.0 \\
Bronchitis & Yes & 462 & 10.4 \\
& No & 30 & 10.0 \\
Wheezing & Yes & 193 & 13.5 \\
& No & 71 & 14.1 \\
Asthma symptoms & Yes & 552 & 17.2 \\
or medication & No & 43 & 18.6 \\
Any breathing & Yes & 341 & 20.8 \\
problems & No & 49 & 18.4 \\
\hline
\end{tabular}

Table 4. - Type of doctor last contacted among subjects reporting contact with a doctor for a breathing problem during the last year, by employment status

\begin{tabular}{llrrrr}
\hline $\begin{array}{c}\text { Symptom or } \\
\text { disease }\end{array}$ & Employed & $\begin{array}{c}\text { Subjects } \\
\text { with } \\
\text { symptoms } \\
\mathrm{n}\end{array}$ & $\begin{array}{c}\text { GP } \\
\%\end{array}$ & $\begin{array}{c}\text { Spec. } \\
\%\end{array}$ & $\begin{array}{c}\text { Other* } \\
\%\end{array}$ \\
\hline Morning cough & No & 3 & 33 & 33 & 33 \\
Morning phlegm & Yes & 42 & 38 & 55 & 7 \\
& No & 7 & 57 & 29 & 14 \\
Bronchitis & Yes & 48 & 35 & 52 & 13 \\
& No & 3 & 0 & 67 & 33 \\
Wheezing & Yes & 26 & 27 & 62 & 12 \\
& No & 10 & 70 & 30 & 0 \\
Asthma symptoms & Yes & 95 & 36 & 56 & 8 \\
or medication & Yes & 8 & 50 & 38 & 13 \\
Any breathing & No & 71 & 34 & 56 & 10 \\
problems & Yes & 79 & 44 & 56 & 0 \\
& & & 29 & 63 & 8 \\
\hline
\end{tabular}

GP: general practitioner; spec.: specialist. *: Other contact: emergency room or hospitalized. : Fisher's exact test. Differences between contact with general practitioner and specialist.

differences by employment status in the type of practitioner last contacted for a breathing problem (table 4). The employed subjects tended to contact specialists more frequently, while the unemployed consulted general practitioners more frequently than specialists. Although these differences were not statistically significant, the pattern was consistent and was seen irrespective of the type and severity of the respiratory symptoms or diseases.

\section{Discussion}

In this general population study among young adults in Spain, it was found that the unemployed had a higher prevalence of respiratory symptoms, which could be attributed only partly to smoking. In addition, unemployed subjects tended to contact specialists for a breathing problem less frequently than those who were employed.

An increased risk was seen for bronchitis-type symptoms, which have consistently been associated with low socioeconomic status [21]. Poverty or relative poverty may be one of the mediating factors for the association between unemployment and a deterioration in health [9]. No direct information was available on the income of the subjects, but information was requested on housing conditions, a factor directly related to poverty. Presence of mould in the house during the last year was reported slightly more frequently by the unemployed subjects, and to some small extent explained the higher risk of disease in these subjects. Unemployment has also been associated with changes in health-related behaviours such as smoking [9]. In this study, similar to other populations [7], the prevalence of smoking was higher among unemployed than employed subjects. Smoking, however, explained only part (about 30\%) of the increased risk of simple chronic bronchitis among the unemployed.

Occupational exposures did not appear to be important mediators of the higher risk for bronchitis-type symptoms among unemployed subjects, although they were associated with asthma in this study [18]. The process between employment and unemployment is dynamic and may entail increasing exposure to occupational hazards. Subjects under the threat of unemployment or those having experienced a spell of unemployment may be more likely to accept hazardous jobs [9] or not to abandon jobs associated with adverse health effects. In this population, however, the unemployed subjects had only a slightly higher prevalence of past occupational exposure to dusts, gases or fumes, and of changes in occupation due to respiratory health problems.

The selection of sick individuals out of employment (selection bias) has been proposed as one of the causes for the higher morbidity of the unemployed population, although the importance of this type of bias has been questioned $[9,11]$. It was not possible to evaluate the extent of this bias in this cross-sectional study, but indirect evidence suggests that any such effect should be small. First, increased risks were observed only for some of the respiratory symptoms examined (bronchitis type), particularly those that have been consistently associated with poverty. Unemployment was not associated with asthma or atopy which, in recent years, has not been clearly related with socioeconomic status [21]. Thus, the unemployed subjects in this population were generally not more prone to sickness. Secondly, only a slightly higher proportion of unemployed than employed subjects reported a change of occupation due to respiratory health problems. This may indicate that respiratory disease was not the cause of the loss of employment, although this statement should be tempered by the possibility of lower job mobility in subjects with unstable employment, even in the presence of health-related symptoms. Complete information on the occurrence of nonrespiratory symptoms or diseases was not available.

There was substantial nonresponse due to the unwillingness of subjects in this young study population to attend the hospital visits. The participation rate was about $60 \%$ for the long questionnaire and $40-50 \%$ for the respiratory and blood tests. This lack of response has not necessarily affected the validity of the results substantially. Biased results would be obtained if the response of subjects with (or without) disease was conditioned on their employment status. The primary aims of the survey were to investigate exposures other than employment status or 
occupation, and it is unlikely that unemployed subjects were selectively convinced to participate in the study. The unemployment rate in the population included in the study was slightly lower than that recorded in municipal statistics of unemployment, which were available for some of the areas of the study [22]. Some of this difference could due to different definitions of unemployment or incompletely overlapping geographical areas or age groups, but it is also possible that the participation rate among the unemployed in the study was lower than that among the employed. A comparison of the sociodemographic characteristics of responders and nonresponders to the short screening questionnaire indicated that they were of similar age, sex and area of residence [16]. Subjects who did not complete the long questionnaire, the methacholine challenge or the blood tests did not show any difference in age and sex from those who participated, although more females with no respiratory symptoms declined to participate than did females with symptoms.

Wide differences were observed regarding the type of healthcare services used. The unemployed patients visited general practitioners more frequently than specialists for respiratory complaints, while the reverse occurred with the employed subjects. Because of the small numbers, these differences were not statistically significant, but the overall pattern was consistent. More frequent contact with primary health and social care centres by the unemployed patients has been reported for centres in the area of Barcelona [23]. By contrast, no substantial differences were seen in the present study population regarding the frequency of contact with the health services, an observation consistent with findings of other studies in industrialized countries with national healthcare systems [12-14]. Contact with a specialist within the Spanish national health service has, usually, to be recommended by a general practitioner and does not imply any additional cost to the patient. Only a small proportion of the population in Spain $(<15 \%)$ is covered by private insurance. It is, therefore, unlikely that the variation in referral patterns is solely due to a more frequent visit by employed (and more wealthy) patients to private specialists. The more frequent referral of the richer patients seems, therefore, to depend on other factors such as the means of decision taking and the level of communication between patients and doctors. The evidence concerning differences in the management of respiratory disease between primary healthcare and specialized practitioners is limited [24, 25], but suggests that the latter provide a more systematic diagnosis and management of respiratory disease. The referral pattern observed in the present study population clearly shows a differential use of specialized health services by employment status within the Spanish national health service, which probably implies differences in the characteristics of the healthcare provided.

In conclusion, in this study, which was conducted among a random general population sample in Spain, a higher risk of respiratory symptoms was observed among unemployed subjects than among employed subjects. These risks could only be associated to a small extent with potential risk factors, particularly smoking. Differences in the use of health services were observed regarding access to specialized health services. Although the observed risks were of moderate magnitude, the high prevalence of unemployment in Spain indicates that a considerable number of spells of disease among the poorest sectors of the society are associated, directly or indirectly, with unemployment.

\section{Appendix}

The Spanish group for the European Community Respiratory Health Survey is composed of: National Coordinator: J.M Antó, Albacete: J. Martínez-Moratalla (coordinator), E. Almar, X. Aguilar, M. Arévalo, A. Mateos, A. Sánchez, A. Teixidó, M. Vizcaya. Barcelona: J. Sunyer (coordinator), F. Burgos, J. Castellsagué, M. Bruna Galobardes, F. Garcia Benavides, M. Kogevinas, J. Roca, J.B. Soriano, A. Tobías. Galdakao: N. Muniozguren (coordinator), M. Errezola, A. Capelastegui, J. Ramos. Huelva: J. Antonio Maldonado (coordinator), J. Luis Sánchez, A. Pereira, J. Grávalos. Oviedo: R. Quirós (coordinator), J. Azofra, L. Palenciano, F. Payo, G. Rego, A. Vega.

\section{References}

1. Moser KA, Jones DR, Fox AJ, Goldblatt PO. Unemployment and mortality: further evidence from the OPCS longitudinal study 1971-81. Lancet 1986; 1: 365-366.

2. Morris JK, Cook DG, Shaper AG. Loss of employment and mortality. Br Med J 1994; 308: 1135-1139.

3. Martikainen P. Unemployment among Finish men. $\mathrm{Br}$ Med J 1990; 301: 407-411.

4. Sorlie PD, Rogot E. Mortality by unemployment status in the National Longitudinal Study. Am J Epidemiol 1990; 132: 983-992.

5. Iversen L, Andersen O, Andersen PK, Christoffersen K, Keiding N. Unemployment and mortality in Denmark 1970-80. Br Med J 1987; 295: 879-884.

6. Costa G, Segnan N. Unemployment and mortality. $\mathrm{Br}$ Med J 1987; 294: 1550-1551.

7. Lynge E. Unemployment and cancer. A literature review. In: Kogevinas M, Pearce N, Susser M, Boffetta P, eds. Social Inequalities in Cancer. Lyon, IARC Scientific Publications, No. 138, 1997.

8. Payne JN, Coy J, Milner PC, Patterson S. Are deprivation indicators a proxy for morbidity? A comparison of the prevalence of arthritis, depression, dyspepsia, obesity and respiratory symptoms with unemployment rates and Jarman scores. J Public Health Med 1993; 15: 161-170.

9. Bartley M. Unemployment and ill health: understanding the relationship. J Epidemiol Community Health 1994; 48: 333-337.

10. Ferrie JE, Shipley MJ, Marmot MG, Stansfeld S, Smith GD. Health effects of anticipation of job change and nonemployment: longitudinal data from the Whitehall II study. Br Med J 1995; 311: 1264-1269.

11. Dahl E. Social mobility and health: cause or effect? $\mathrm{Br}$ Med J 1996; 313: 435-436.

12. Jin RL, Shah CP, Svoboda TJ. The impact of unemployment on health: a review of the evidence. Can Med Assoc $J$ 1995; 153: 529-540.

13. Virtanen P. Unemployment, re-employment and the use of primary health care services. Scand J Prim Health Care 1993; 11: 228-233.

14. Benavides FG, García AM, Sáez-Lloret I, Librero J. Unemployment and health in Spain. The influence of socio-economic environment. Eur J Public Health 1994; 4: 103-107. 
15. Instituto Nacional de Estadistica. Encuesta de Población Activa. Madrid, INE, 1991.

16. Grupo Español del Estudio Europeo del asma. Estudio Europeo del asma. Prevalencia de síntomas relacionados con el asma en cinco áreas españolas. Med Clin (Barc) 1995; 104: 487-492.

17. Burney PGJ, Luczynska C, Chinn S, Jarvis D. The European Community Respiratory Health Survey. Eur Respir J 1994; 7: 954-960.

18. Kogevinas M, Antó JM, Soriano JB, Tobias A, Burney P, on behalf of the Spanish Group for the European Asthma Study. The risk of asthma attributable to occupational exposures. A population based study in Spain. Am J Respir Crit Care Med 1996; 154: 137-143.

19. SAS Institute. SAS/STAT User's Guide. Cary, NC, SAS Institute Inc., 1989.
20. Statistics and Epidemiology Research Corporation and Cytel Software Co. EGRET, 1990.

21. Colley JRT. Respiratory system. In: Holland WW, Detels R, Knox G, eds. Oxford Textbook of Public Health, Vol. 4. Oxford, Oxford University Press, 1985; pp. 145-166.

22. Resum Estadistic per 38 zones. Departament d'estadistica de Barcelona. Ajuntament de Barcelona, 1993.

23. Doz Mora JF, Mengual L, Torné M, Bonilla P. Poverty and disease: users of the primary care social services of a primary care center. Aten Primaria 1994; 14: 563-566.

24. Vermeire P. Differences in asthma management around the world. Eur Respir J 1994; 4: 279-281.

25. Naberán Toña C. Encuesta de la actitud terapéutica y de control de los médicos generales de las ABS de Barcelona, respecto a enfermedades obstructivas respiratorias. Aten Primaria 1994; 13: 112-116. 